\title{
Jahrestagung 1973
}

Die Vereinigung der Deutschen Staatsrechtslehrer versammelte sich vom 3. bis 6. Oktober 1973 in Mannheim. Der Vorsitzende, Herr Hesse (Freiburg), konnte wiederum eine sehr stattliche Zahl von Mitgliedern mit ihren Damen, Gäste, insbesondere aus Japan, und Vertreter der Fachpresse begrüßen. Das Mannheimer Schloß als Sitz der modernen Universität in der lebendigen Stadt bildete einen großzügigen Tagungsort. Der Rektor der Universität begrüßte die Vereinigung. Der Vorsitzende gab dem Dank der Vereinigung Ausdruck; er hob zugleich die Verdienste hervor, die sich Herr Bartlsperger (Mannheim), Frau Bartlsperger sowie die an der Vorbereitung beteiligten Mitarbeiter um das Gelingen der Tagung in besonderem Maße erworben haben.

Die Mitgliederversammlung gedachte der im vergangenen Jahr verstorbenen Angehörigen der Vereinigung, darunter ihres Ehrenpräsidenten Erich Kaufmann, mit dem die Wissenschaft des öffentlichen Rechts einen ihrer großen und prägenden Repräsentanten verloren hat. Der Bericht des Vorstands ging u. a. auf die Resonanz der in Salzburg beschlossenen Empfehlungen zur Gestaltung des Studiums im Wahlfach Verwaltungslehre sowie auf Aktivitäten zur Verwirklichung der Regensburger Empfehlungen ein. Uber die Beratungen des Gesprächskreises Verwaltungslehre berichtete Herr Weber (Göttingen). 19 neue Mitglieder konnten aufgenommen und vorgestellt werden. Zum neuen Vorstand der Vereinigung wurden die Herren Ipsen (Hamburg), Vogel (Heidelberg), Ossenbühl (Bonn) gewählt.

Die Tagung wurde durch eine Reihe festlicher Veranstaltungen umrahmt. Die Landesregierung Baden-Württemberg und die Stadt Mannheim gaben einen Empfang im Rittersaal des Schlosses. Kunstgeschichtliche Führungen, gesellige und sonstige Veranstaltungen sowie eindrucksvolle Ausflüge in die Umgebung mit ihren reichen landschaftlichen Schönheiten und Baudenkmälern erfreuten die Teilnehmer und festigten die persönliche Verbindung.

Die nachstehend abgedruckten Referate wurden am 4. und 5. Oktober 1973 in der Universität Mannheim gehalten. An sie schlossen sich jeweils die Aussprachen an. 
